\title{
ANALYSIS AND CHOICE OF ROUTING PROTOCOLS IN WIRELESS AD HOC NETWORKS BASED ON THE USE THE NEURAL NETWORK
}

\author{
Oleksandr Oksiiuk ${ }^{1}$, Vadym Krotov ${ }^{2}$ \\ ${ }^{1}$ Taras Shevchenko National University of Kyiv, ${ }^{2}$ Heroes of Krut Military Institute of Telecommunications and Informatics
}

Abstract. In the past few years, we have seen a rapid expansion in the field of mobile computing due to the proliferation of inexpensive, widely available wireless devices. However, current devices, applications and protocols are solely focused on cellular or wireless local area networks (WLANs), not taking into account the great potential offered by ad hoc networking. Ad hoc networks are wireless mobile networks that can operate without infrastructure and without centralized network management. In such networks, the wireless mobile nodes may dynamically enter the network as well as leave the network. Mobility and dynamic topology are the main characteristics of ad hoc networks. In the last years, the hundreds of new routing protocols were designed, that are used for the various scenarios of this design space. The routing features in wireless ad hoc networks are described. The corresponding routing protocols are reviewed. The paper proposes a method for selecting the preferred protocol wireless networks using the mathematical tools of neural networks.

Keywords: routing protocol, wireless ad hoc networks, throughput of network, neural network, networks of special appointment

\section{ANALIZA I WYBÓR PROTOKOLÓW ROUTINGU W SIECIACH BEZPRZEWODOWYCH AD-HOC W OPARCIU O SIECI NEURONOWE}

\begin{abstract}
Streszczenie. Obecnie intensywnie rozwija się kierunek naukowy $w$ zakresie budowy sieci telekomunikacyjnych o zmiennej topologii z wykorzystaniem urządzeń bezprzewodowych. Jednak istniejace urzadzenia i protokoty koncentruja się wyłacznie na komórkowe lub bezprzewodowe lokalne sieci (WLAN), niezależnie od potencjału sieci Ad-Hoc. Sieci Ad-Hoc sa to sieci bezprzewodowe, które moga pracować bez infrastruktury i bez scentralizowanego zarzadzania siecia. W takich sieciach węzły moga dynamicznie poruszać się po sieci. Mobilność oraz dynamiczna topologia to kluczowe cechy sieci AdHoc. W ostatnich latach opracowano wiele protokołów dla sieci Ad-Hoc zaprojektowanych dla różnych scenariuszy organizacji routingu. Opisano funkcje routingu $w$ sieciach bezprzewodowych Ad-Hoc i przedstawiono przegląd odpowiednich protokolów routingu. W artykule zaproponowano metodę wyboru protokolu sieci bezprzewodowej z wykorzystaniem matematycznego aparatu sieci neuronowych.
\end{abstract}

Słowa kluczowe: protokół routingu, bezprzewodowe sieci Ad-Hoc, sieć neuronowa, sieć dedykowana, sieci specjalnego przeznaczenia

\section{Introduction}

Nowadays, there is a tendency in scientific world concerning the construction of communication networks with variable topologies named "Ad Hoc networks", and this tendency is developing intensively. Ad Hoc network is a wireless network with dynamic topology, which consists of mobile nodes and does not have fixed infrastructure [7]. Each network node sends data appointed for other nodes. So, node eve should send all data dynamically on the grounds of network connectedness. The difference between wire (conducting) networks and wireless ones is in the task to operate the streams of data is done by routers (in wire networks) or points of access (in wireless networks). Minimum configuration and quick development allow the usage of these networks in various situations including military conflicts.

Ad Hoc networks have the following advantages over wireless networks of traditional architecture. They have a possibility to transmit data at long distances without enlarging power of a transmitter; firmness to changes in network infrastructure; possibility of quick reconfiguration under the conditions of unfavorable situation; simplicity and high speed of development.

Wireless networks constructed on the basis of mobile devices have a lot of peculiarities: mobility of nodes leads to the additional increase of dynamics of network topology, so it causes the possibility of breaking transmission because of the obstacles or switching on/ switching off /of node the authenticity of its transference is added; the store of sources feeding of mobile nodes may be limited. That's why while projecting device means and protocols it's necessary to take into account the power consumption.

Nowadays we can distinguish some problems of Ad Hoc networks:

- the problem of providing of obstacle;

- the problem of the protection of transmitted data;

- the problem of general productive capacity of networks;

- the problem of effectiveness of the used methods of routing. As a result, protocols and technical decisions, used in classical wire networks of telecommunications, become ineffective [7].
Protocols of routing must have the following qualities for successful use in Ad Hoc networks:

1 They must be distributed. All network nodes have to be able to perform routing and they should not possess functions strictly appointed to them.

2 To ensure safe delivery of packages under the conditions of dynamic network topology, the use of classical mechanisms of guaranteed transmission is rather complicated.

3 To ensure the minimum time of making the route in the conditions of network topology which is constantly changing.

4 To have mechanisms of fast revealing of the broken route and its renovation.

5 Don't let the formation of loops in routes.

6 To transmit the minimum amount of official information while functioning.

7 To have a high scale, that is to ensure a high productivity of network of different sizes.

8 To support QoS.

\section{Research and Publication Analysis}

A lot of approaches to formalization and decision of routing tasks were developed in papers $[1,3,6,8,9,15]$, that were founded on using of various mathematical models depending on chosen criterion.

Research of routing protocols of Ad Hoc networks on the basis of modeling in NS-3 has been held in papers [10, 11].

But the ideas given are abstract and do not have the practical realization. Identical comparison of protocols from the point of theory is complicated because a great number of different factors influences the process of transferring data in Ad Hoc networks. A lot of factors have casual character and yield faintly to the strict mathematical analysis.

\section{Main Part of Research}

According to the existent classification $[2,7,13]$ the protocols of routing in Ad Hoc networks are divided into three main groups as for strategy of routing (Fig. 1). 


\section{Protocols of Routing in Ad Hoc networks}

Proactive

Open Shortest Path First (OSPF)

Optimized Link State Routing (OLSR)

Topology Broadcast Based on Reverse Path Forwarding (TBRPF)
Reactive

Ad hoc On-demand Distance Vector (AODV)

Ad hoc On-demand Multipath Distance Vector routing (AOMDV)

Temporally-Ordered Routing Algorithm (TORA)

Dynamic Source Routing (DSR)

Routing on-demand acyclic multi-path (ROAM)

Split Multipath Routing (SMR)

CacHing And Multipath routing Protocol

(CHAMP)

Multipath Source Routing (MSR)
Fig. 1. Classification of protocols of routing for Ad Hoc networks

Proactive protocols transmit through networks official messages with the information about all changes in its topology. As a result every network node forms routes to all other nodes on the basis of this information and saves them in the routing table. Later on this information is used for necessary transmission of information to any addressee.

Reactive or working on-demand protocols form routes to definite nodes in case of necessity to transmit information to it. For this the node-transmitter sends broadcasting through the networks a message-demand that must reach the nodeaddressee. The addressee sends a message-confirmation as an answer. And the transmitter finds out about necessary route and records it into its table of routing. For the repeated transmission of messages of the addressee the route is read in the table. If its destruction is revealed so-called the procedure of route support is launched, which is a search of a new route to the addressee.

Hybrid protocols combine mechanisms of proactive and reactive ones. As a rule, they split a network into a number of subnet in which a proactive protocol is operating and the interference between them is made with the help of reactive protocols.

There are separate well-known examples of the right choice of protocol, received by the experiment method for some meanings of average node mobility, number of nodes and kind of tasks. So, it's necessary to work out a formal mathematical device that allows choosing a preferential protocol for different definitions of mobility, number of nodes and tasks. Neural networks are valid of application as such instrument.

The article presents the methods of choice of the most acceptable protocol of Ad Hoc network. As the mobility of nodes and amount of Ad Hoc networks can be changed in course of time. Then the choice of preferential protocol has to be made considering these changes.

The amount of work depends on networks tasks that are carried out in nodes of network. It's expected that equipment which maintains the work of Ad Hoc network can work under the management of various protocols and can shift dynamically from one protocol to another.

Consider the next classes of network tasks [14]:

- organization of e-mail, transmission of files;

- organization of removed access;

- transmission of audio and video files on demand;

- organization of telephony, videoconference.

We guess the tasks of only chosen classes are solved in the nodes of network. Effectiveness of solving appointed tasks depends on the following indices [14]: reliability of package delivery, delay of package delivery, fluctuation package delivery delay and productive capacity. In the whole these indices characterize the Quality of Service.
Such network tasks, as: organization of e-mail, file transmission, organization of removed access put forward high demands only for the index reliability of package delivery. If a packet was spoilt it is sent again. The definite tasks are insensitive to other indications.

In [4] as a result of modality protocols AODV, DSR, DSDV it's indicated that:

1 Under high mobility of nodes protocol DSR has got better meaning of indications of removed packets and average time of transmission packets as to compare with protocol DSDV.

2 When we enlarge the number of nodes the protocol DSDV has got better meanings of the same indications in comparison with protocols DSR and AODV.

3 For network tasks that operate in conditions of real-time, the protocol AODV is more acceptable, than protocols DSR and DSDV, because when enlarging the number of nodes, the time of transmission of packets in network changes a little while using the protocol AODV. In addition, mentioned network tasks are sensitive for fluctuations of time transmission packets.

4 The protocol DSDV is more effective than protocols DSR and AODV for networks with a little number of nodes and a low mobility.

For solving task as for choosing acceptable routing protocol the neural network which has got one hidden layer $[12,16]$ has been chosen. As the quantity of neurons in the hidden layers usually fluctuates from $N_{x}$ to $3 N_{x}, N_{x}$ means number of entries of neural network to determine the number of neurons in a hidden layer that equals five. Considering three versions of network technologies, the number of entries and outlet of neural network equals three.

Let's introduce the following marks:

$x_{1}$ - average mobility of nodes, $1>x_{1}>0$;

$x_{2}$ - number of predominant class of tasks in the network nodes;

$x_{3}$ - quantity of nodes in network;

$y_{1}$ - value that equals unit while choosing of protocol AODV and naught in all other cases;

$y_{2}$ - value that equals unit while choosing of protocol DSR and naught in all other cases;

$y_{3}$ - value that equals unit while choosing of protocol DSDV and naught in all other cases.

The structure of neural network on the basis of two-layer perceptron is presented on figure 2 .

For studying and testing of neural network algorithm has been used and put into effect with the help of the library DELPHI NeuralBase.

Studying selection consisted of 300 examples in which the number of network nodes changed from 2 to 1000 , and number of predominant class - from 1 to 4 , average mobility of nodes - from 0.01 to 0.9. Average quadratic mistake that was in all examples is 0.00027 . 


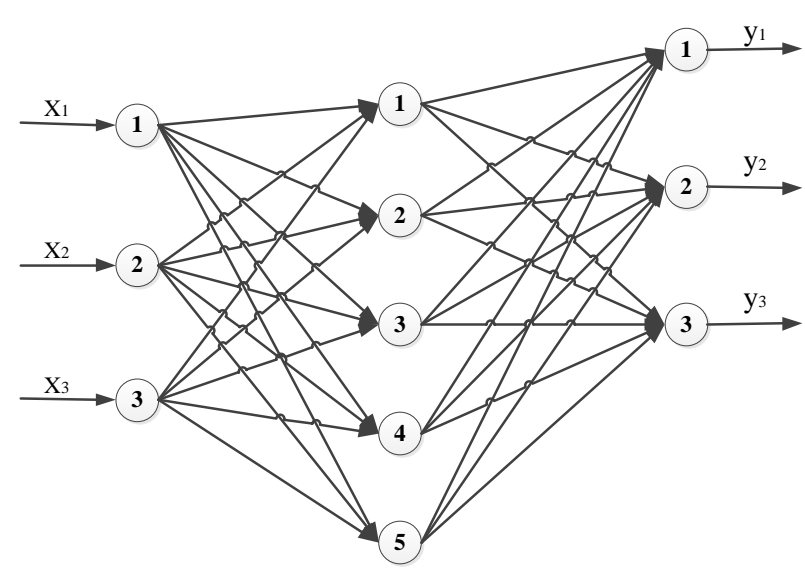

Fig. 2. Two-layer perceptron for choosing of protocol

The test choice from 10 examples has been used to appreciate (all) capacity of neural network for summing up at studying of neural network. Average quadratic mistake that was in all test examples equals 0.00102. It is supposed that all mistakes of studying and summing up are acceptable. Let's consider the process of protocol choosing in wireless network.

Choosing of protocol is made according to the program at one of nodes wireless network.

1 At every node of wireless network the program is realized. This program with given frequency transmits to the controlling node parameters of its node: number of class tasks and mobility.

2 After getting parameters from all nodes the program which was loaded at the controlling node, makes choice of the protocol of wireless network with the help of neural network.

3 Then the program at the managing node transmits the command of transition another nodes of network into the chosen protocol.

The frequency of parameters transmission to the managing node from the other nodes of network is given for setting programs in the nodes. To value of effectiveness of chosen (by neural network) protocol a certificate - time of transferring of packets has been used. As a result of the experiment, made with the taught neural network the dependence of effectiveness of chosen by neural network of protocol upon the number of nodes introduced in picture 3 has been received.

Efficiency Eff for every protocol (DSR, AODV, DSDV) was demined as a coefficient of absolute acceleration with the following formula:

$$
\text { Eff }=\frac{T_{1}}{T_{2}}
$$

$T_{1}$ - time of transferring packets using one of protocols;

$T_{2}$ - time of transferring packets using chosen by neural network protocol.

With little quantity of nodes, for example 10 (Fig. 3), the coefficient of absolute acceleration of chosen (by neural network) protocol can be equal 1.1, that's $10 \%$ better in comparing with other protocols. Transition to the new protocol of transmission data in the network cannot take place at once. For this, it is necessary to save current state in the nodes of network, to disrupt connections and repeated reconnection. Certainly, transition to the new protocol is reasonable when effect, received from the use of chosen protocol exceeds time expenses connected with passing over this protocol.

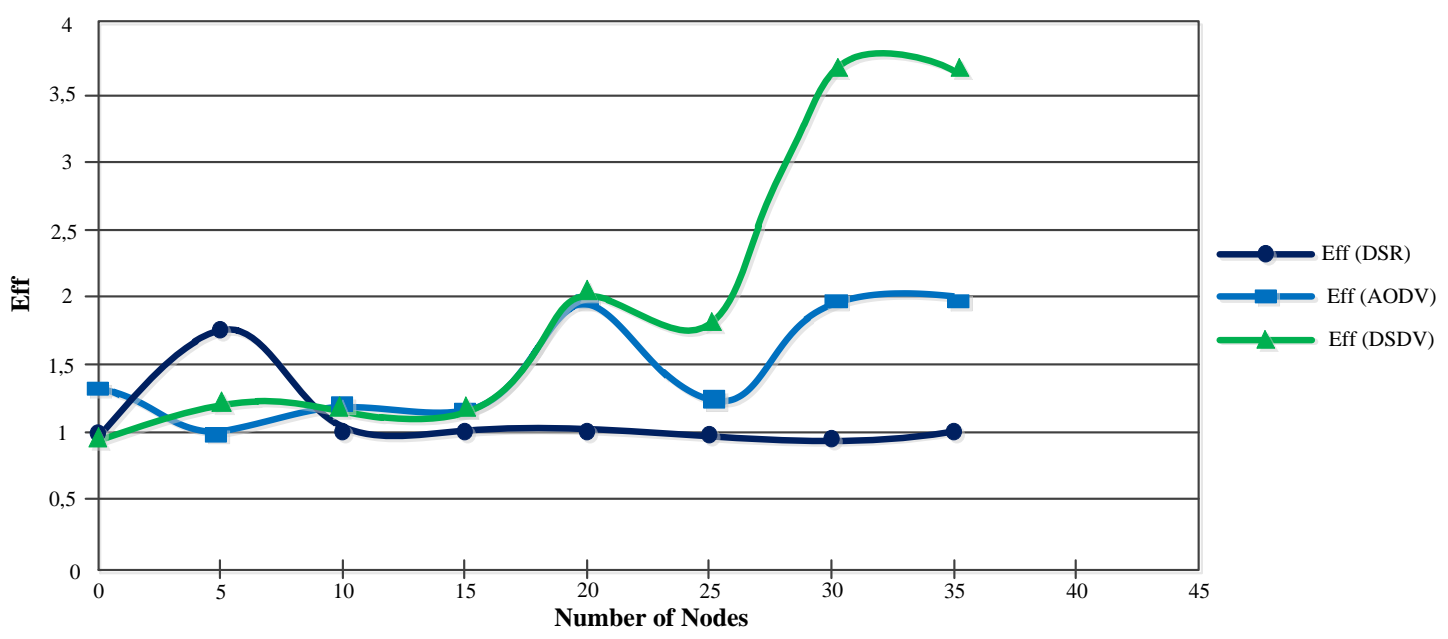

Fig. 3. Dependence of the coefficient of absolute acceleration on quantity of nodes

In connection with this preliminary value of time delivery of packets for various protocols on one lot of network is needed. To get similar values of another neural network with the same structure is used. This network is presented in figure 2, with entries $x_{1}, x_{2}, x_{3}$ and outlets $T_{D S R}, T_{A O D V}, T_{D S D V}$, where $T_{D S R}, T_{A O D V}$, $T_{D S D V}$ is the time of delivery packets according protocols DSR, AODV, DSDV accordingly. After the studies of this neural network it allows to get meaning $T_{D S R}, T_{A O D V}, T_{D S D V}$ for given inlet data.

Mark with $y^{*}=F\left(x_{1}, x_{2}, x_{3}\right)$ - function for choosing prevailing protocol with the first neural network that acquires values $1,2,3$, that corresponds selected protocols DSR, AODV, DSDV.

Mark $T_{D S R}{ }^{*}, T_{A O D V}{ }^{*}, T_{D S D V}{ }^{*}$ - functions of time delivery of packets for protocols DSR, AODV, DSDV (are determined with the second neural network).
Then in (1) is determined like this [6]:

$$
\begin{gathered}
T_{1}=\frac{1}{2}\left(y^{*}-2\right)\left(y^{*}-3\right) T_{D S R^{*}}-\left(y^{*}-1\right)\left(y^{*}-3\right) T_{A O D V^{*}}+ \\
+\frac{1}{2}\left(y^{*}-1\right)\left(y^{*}-2\right) T_{D S D V^{*}}
\end{gathered}
$$

Imagine, that state of network has changed, parameters $x_{1}, x_{2}$, $x_{3}$ have got growth $x_{1}+\Delta x_{1}, x_{2}+\Delta x_{2}, x_{3}+\Delta x_{3}$. Then the state of neural network $y=F\left(x_{1}+\Delta x_{1}, x_{2}+\Delta x_{2}, x_{3}+\Delta x_{3}\right)$ corresponds to a new chosen protocol. $T_{D S R}, T_{A O D V}, T_{D S D V}-$ new marks of time delivery packets, which have been obtained with the second neural network, and in (1) are defined like this:

$$
\begin{gathered}
T_{2}=\frac{1}{2}(y-2)(y-3) T_{D S R}-(y-1)(y-3) T_{A O D V}+ \\
+\frac{1}{2}(y-1)(y-2) T_{D S D V}
\end{gathered}
$$


Substitute (3) and (2) in (1) and acquire value of the coefficient of absolute acceleration

$$
E f f=\frac{\frac{1}{2}\left(y^{*}-2\right)\left(y^{*}-3\right) T_{D S R^{*}}-\left(y^{*}-1\right)\left(y^{*}-3\right) T_{A O D V^{*}}+\frac{1}{2}\left(y^{*}-1\right)\left(y^{*}-2\right) T_{D S D V^{*}}}{\frac{1}{2}(y-2)(y-3) T_{D S R}-(y-1)(y-3) T_{A O D V}+\frac{1}{2}(y-1)(y-2) T_{D S D V}}
$$

As for formula (4), we compute the coefficient of absolute acceleration Eff of selected protocol during time of transmission packets. If it is less of any threshold Eff min that is given in the program of operating node then the transition to the chosen protocol with the first neural network is not realized.

First neural network makes choice of prevailing protocol. Based on different certificates like: time of transition packets, number of removed packets and the like. The second neural network defines expediency of transition to the protocol, chosen by the first neural network by means of comparison effectiveness of selected protocol according the times of delivery packets with some threshold value, determined experimentally by taking into account time of passing over to a new protocol.

\section{Conclusion}

Routing in Ad Hoc networks is much more complicated, than in wire ones, from the point of view of dynamic topology of Ad Hoc networks. Three categories of routing protocols as: proactive, reactive and hybrid ones are discussed in the article. Taking into account this, an effective set of instruments of choice of predominant Ad Hoc routing protocol has been developed and founded on the use of mathematical device of neural networks. It's indicated that the use of a developed set of instruments can win in rapidity of transmission of packets more than 2 times.

From now on, it is planned to compare other routing protocols by means of imitation modelling of their functioning in different conditions to use in networks of special appointment. On the basis of analysis of received results it is planned to enter into the most perspective protocols of completeness's, that raise their effectiveness or to form on their basis a new protocol for Ad Hoc networks of special appointment.

\section{References}

[1] Anisur R., Shohidul I., Talevski A. Performance Measurement of Various Routing Protocols in Ad-hoc Network. Proceedings of the International Multi Conference of Engineers and Computer Scientists 2009 - IMECS 2009, Hong Kong 2009.

[2] Boukerche A.: Algorithms and protocols for wireless, mobile ad hoc networks. John Wiley \& Sons Inc., New Jersey 2009.

[3] Das S. R., Perkins C. E., Royer E. M.: Performance comparison of two ondemand routing protocols for ad hoc networks, in Proceedings of the IEEE Conference on Computer Communications - INFOCOM, Tel Aviv 2000.

[4] Kaushik S. S., Deshmukh P. R.: Comparison of effectiveness of AODV, DSDV and DSR routing protocols in mobile Ad hoc networks. International Journal of Information Technology and Knowledge Management 2(2)/2009, 499-502.
[5] Komashinsky V. I., Smirnov D. A.: Neyronnyyeseti i ikh primeneniye v sistemakh upravleniya i svyazi. Goryachaya liniya - Telecom, Moscow 2003.

[6] Li M.et al: An Energy-Aware Multipath Routing Protocol for Mobile Ad Hoc Networks, ACM Sigcomm, Beijing 2005, 10-12.

[7] Morais Cordeiro, de C., Agrawal D. P.: Ad hoc and Sensor Networks, Theory and Applications. World Scientific Publishing Co, Singapore 2006.

[8] Nasipuri A., Das S. R.: On-Demand Multi-path Routing for Mobile Ad Hoc Networks, IEEE ICCCN'99, 64-70.

[9] Park V. D., Corson M. S.: A highly adaptive distributed routing algorithm for mobile wireless networks. Proceedings of the IEEE Conference on Computer Communications - INFOCOM, Kobe 1997, 1405-1413.

[10] Perkins C. E., Bhagwat P.: Highly Dynamic Destination Sequenced Distance Vector Routing (DSDV) for Mobile Computers. Sigcomm, 1994, 234-244.

[11] RFC 3561 - Ad hoc On-Demand Distance Vector (AODV) Routing. The Internet Engineering Task Force (IETF). URL: http://www.ietf.org/rfc/rfc3561.txt. (Available: 10.10.2018).

[12] Rogozin O.V.: Otkrytoye obrazovaniye, 6/2010, 140-146.

[13] Sarkar N. I., Lol W. G.: A Study of MANET Routing Protocols: Joint Node Density, Packet Length and Mobility. IEEE 2010, 515-520.

[14] Tanenbaum E.: Komp'yuternyye seti. 4th ed. Piter, Saint Petersburg 2003.

[15] Yang W. et al.: A Bandwidth Aware Multi-path Routing Protocol in Mobile Ad Hoc Networks. Journal of Computational Information Systems 7(3)/2011, 685-696.

[16] Yasnitsky L.N.: Vvedeniye v iskusstvennyy intellekt. Academy, Moscow 2005.

\section{Prof. Oleksandr Oksiiuk}

e-mail: oksiuk@ukr.net

The main areas of research practice of building intelligent systems, fuzzy control algorithms, logic and linguistic modeling in cyberspace, the theory and practice of designing automated systems and expertise models and methods for building and expertise models and methods for building a comprehensive information security system
of the entity engaged in information activities. Held position Head of Department of Cyber Security and Information Protection, Taras Shevchenko National University, Kyiv. Pedagogical and scientific experience more than of 30 years.

Research activities: information security of telecommunication systems and networks, information systems, information security systems

ORCID ID: 0000-0001-9797-6015

\section{Ph.D. Vadym Krotov}

e-mail: a-078128@ukr.net

Began a scientific career in 2008. In 2018, he entered the Adjuncture for the degree of Ph.D. (technical sciences). Prior to the adjuncture, he held the position of Leading researcher at the Military Institute of Telecommunications and Informatization, Kiev. Scientific experience over 10 years.

Research activities: routing in special-purpose networks, data queue fuzzy management in Ad Hoc networks. Author (co-author) of more than 20 scientific papers and methodical publications.

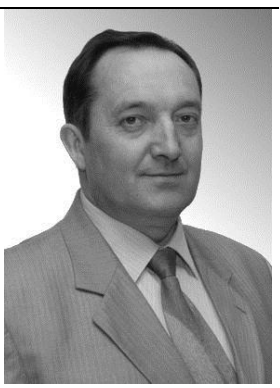

ORCID ID: 0000-0001-5696-3496

otrzymano/received: 01.12 .2018

przyjęto do druku/accepted: 28.02 .2019 